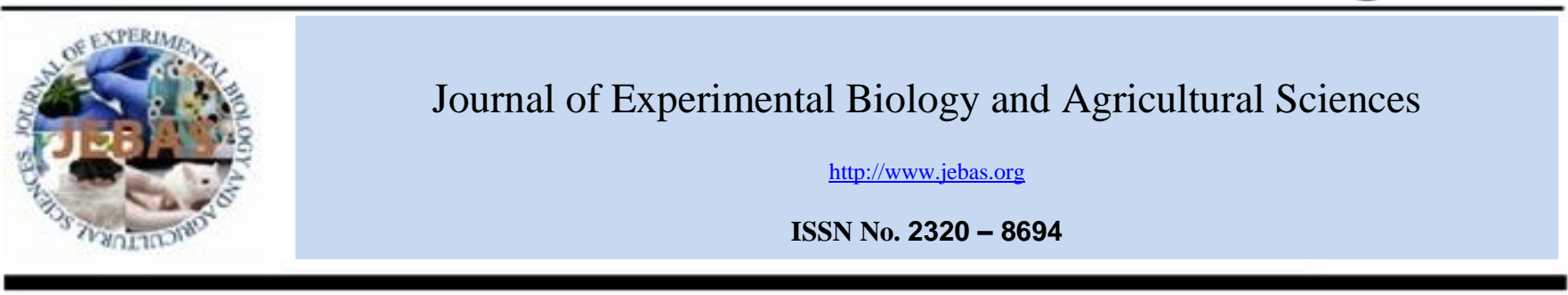

\title{
EXTENSIVE SYNOVIAL CHONDROMATOSIS OF SHOULDER: A CASE STUDY FROM SHIRAZ, IRAN
}

\section{Omidreza Momenzadeh ${ }^{1}$ and Mohammad Javad Farahani ${ }^{2, *}$}

\footnotetext{
${ }^{1}$ Associate Professor of Orthopedic Surgery, Bone and Joint Disease Research Center, Shiraz University of Medical Sciences, Shiraz, Iran

${ }^{2}$ Resident of Orthopedic Surgery, Bone and Joint Disease Research Center, Shiraz University of Medical Sciences, Shiraz, Iran
}

Received - October 17, 2016; Revision - November 10, 2016; Accepted - December 07, 2016

Available Online - December 30, 2016

DOI: http://dx.doi.org/10.18006/2016.4(VIS).756.760

\section{KEYWORDS}

Shoulder

Synovial chondromatosis

Open arthrotomy

\begin{abstract}
Synovial chondromatosis is the rare and benign metaplasia of the synovial membrane resulting in the formation of multiple intra-articular cartilaginous bodies. This study was conducted on 28 years old male who was suffering from severe pain and limitations of motion in right shoulder since 2 years ago, which developed gradually, accompanied with night pain. Previous results and available literature suggested the use of arthrotomy or arthroscopy for the treatment of synovial chondromatosis of shoulder. In present study also both the treatment methods are effective but lesion open arthrotomies are found more effective due to some cases related to extension. Further, it was concluded that better results can be obtained on the early intervention of disease.
\end{abstract}

* Corresponding author

E-mail: farahani_mohammad2005@yahoo.com (Mohammad Javad Farahani)

Peer review under responsibility of Journal of Experimental Biology and Agricultural Sciences.

Production and Hosting by Horizon Publisher India [HPI] (http://www.horizonpublisherindia.in/).

All rights reserved.
All the article published by Journal of Experimental Biology and Agricultural Sciences is licensed under a Creative Commons Attribution-NonCommercial 4.0 International License Based on a work at www.jebas.org.

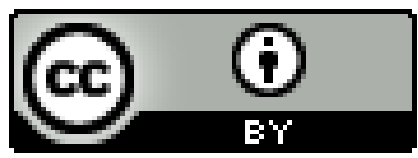




\section{Introduction}

Leannac (1813) was the first one who described the term synovial chondromatosis while the current knowledge regarding this disease was based on the description given by Jaffe in 1958 (Jaffe, 1958; Crotty et al., 1996; Dorfman \& Czerniak, 1998; Fanburg-Smith, 2003; Hopyan et al., 2005). Recently used, cytogenetic evaluation suggested that synovial chondromatosis is a rare benign neoplasm which is caused by metaplasia of the synovium into chondrocytes (Springer,1991; Mertens et al.,1996). Synovial chondromatosis is characterized by the formation of metaplastic and multiple foci of cartilage in the intimal layer of the svnovial membrane of a joint (Davis et al., 1998a; Tachdjian,1990). The aetiology of synovial chondromatosis is indecisive but Miligram (1977) classified the three stages viz early (active intrasynovial disease but no loose bodies), transitional disease (active disease and loose bodies), and late (multiple loose bodies but no intrasynovial disease).

The term synovial osteo-chondromatosis is used when the cartilage is ossified. The lesion also occurs in bursae and tendon sheaths (Sviland \& Malcolm, 1995). This condition usually seen in knee, hip, or elbow, but it is rare in the shoulder (Varrna \& Rarnakrishna, 1976, Volpin et al., 1980, Leo \& Nocera, 1981). It usually occurs in persons older than 40 years of age but occasionally occurs in adolescents It predominantly occurred in men and frequency of synovial chondromatosis in men is twice than the women.

Arthrotomy caused the thickened synovium and studded with innumerable small, firm, flat or slightly raised grayish-white nodules. These cartilaginous or osteocartilaginous foci may become pedunculated and detached from the affected membrane, entering the joint cavity as loose bodies. Histologic

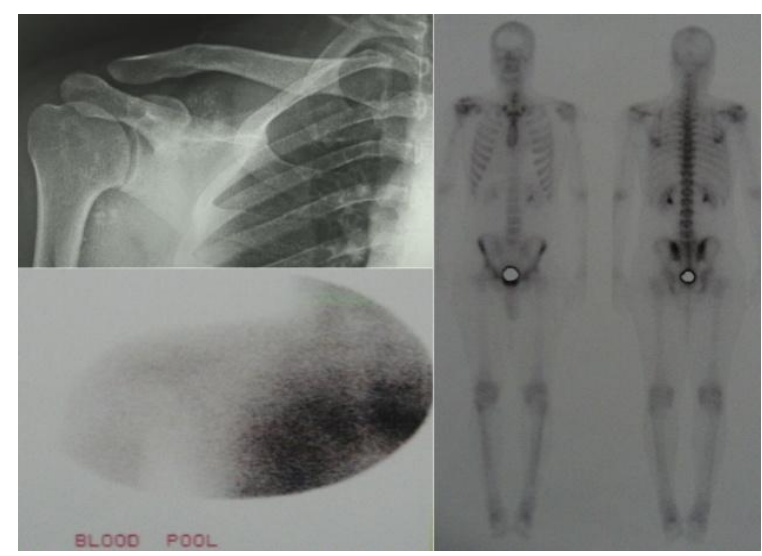

Figure $1 \mathrm{X}$-ray and bone scan of Rt shoulder (increased blood pool and delay uptake) of patient shows synovial chondromatosis. studies disclose numerous foci of cartilaginous metaplasia of the synovium, which may be calcified or ossified.

Clinical complaint consist pain, swelling and stiffness to the affected joint. Further, joint may lock when there is loose body (Murphy et al., 1962; Trias \& Quintana, 1976; Roulot \& Le Viet, 1999; Butt et al., 2005). Month or years may elapse before patients seek treatment. On examination the synovial membrane is noted to be thickened and the joint is limited in its range of motion. Other physical signs that can be elicited are crepitus and palpable loose bodies.

\section{Case Presentations}

A 28 years old caucasian male came to Chamran hospital's orthopedic clinic, Shiraz, Iran with Rt shoulder pain. The patient had pain since 2 years and it became gradually worsen and developed pain on motion and there after limitation of motion. Further, the patient explained night pain about 2 month before surgery.

In physical examination the patient had mild swelling inferior aspect of Rt clavicle at distal 3rd.The range of motion was significantly decreased in all direction accompanied with severe pain. Further, weakness in deltoid muscle was apparent. The neuro vascular examination of Rt shoulder showed upper extremity was intact. The paraclinic lab data which taken recently before the reference showed no abnormality. The Rt shoulder X-Ray showed multiple areas with stippled calcification in and around the shoulder joint which extend to middle 3rd of clavicle and other hand to proximal of humerus (Figure 1). Bone scan suggested mild arthritis in Rt shoulder (FIGURE 1), while MRI screening revealed a significant amount of joint effusion with multiple size hypointense lesion and supraspinatus tendinosis (Figure 2).

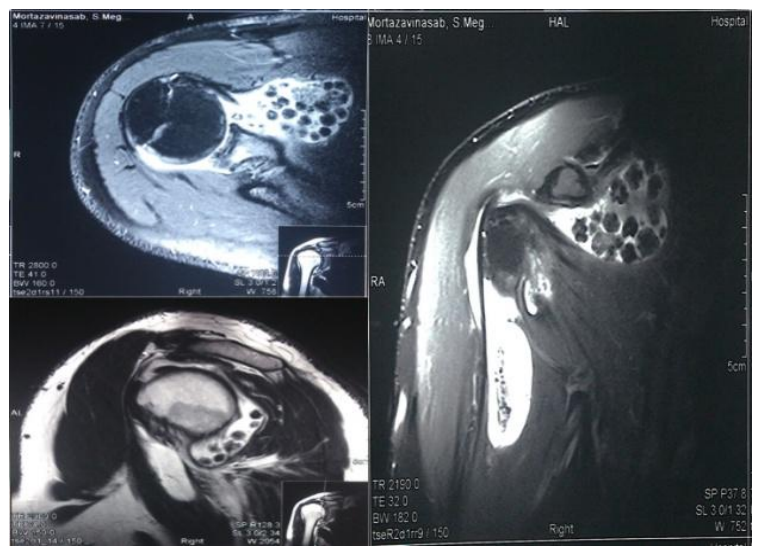

Figure 2 Axial, coronal and sagittal view of Rt shoulder. 
Detail diagnose suggested the occurrence of synovial chondromatosis. The patient admitted to Chamran hospital orthopedic center for surgery. Due to extension of osteocartilagenous fragment till middle 3rd of clavicle and till inferior pouch of shoulder joint, we decided to do open arthrotomy of Rt shoulder. The patient underwent operation through deltopectoral approach and evacuation of many fragments and partial synovectomy were done through arthrotomy of shoulder joint (Figure 3).

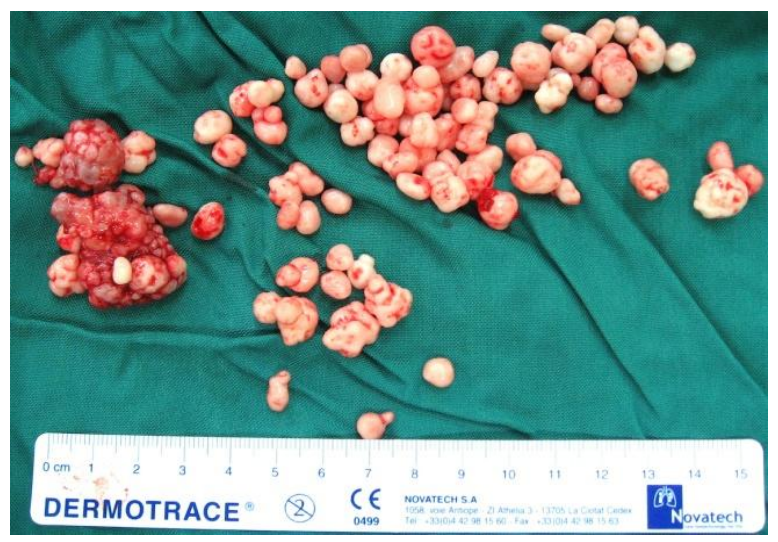

Figure 3 Synovial chondromatosis fragments.

After operation rehabilitation started 2 days and patient discharged 4 days after the surgery. The patient followed for 9 month who had full range of motion (Figure 4) without pain with normal imaging.

\section{Discussions}

Three phases of articular disease have been identified these are

(i) Initial phase which is characterized by the formation of metaplastic cartilaginous nodules in the synovium. This was followed by the .

(ii) Transitional phase characterized by the detachment of these nodules and formation of free intra-articular bodies. The last phase is known as inactive phase in this resolution of synovial proliferation occurred and loose bodies remain in the joint, and may increase in size obtaining nourishment from the joint fluid by diffusion. Similar type of stages was reported by the Miligram (1977).

Chong et al. (2007) suggested that non-steroidal antiinflammatory drugs can be used along with transcutaneous therapies (eg, ultrasound, thermal therapies) for reduction of inflammation. Patients with primarily mechanical symptoms do not benefit significantly from non operative therapy. Further, Chong et al. (2007) also demonstrated that radiotherapy is a successful modality which can use for synovial chondromatosis of the knee refractory to several previous surgical interventions.
The traditional surgical approach consisted of an open arthrotomy of the joint, with removal of all loose bodies and either a partial or a full synovectomy, but now in these days standard treatment is arthroscopic examination and excision of loose bodies, with limited synovectomy of involved synovium only but local recurrence is not uncommon and occurred only in 3 - 23\% cases (Davis et al.,1998b; Murphey,2007).

Malignant degeneration was also reported in chondrosarcoma but very rarely (Kenan et al.,1993). Additionally, the cellular atypia was also demonstrated as synovial ostreochondromatosis and in some instances this may be misinterpreted as chondrosarcoma, and thus a true rate of malignant degeneration is uncertain.

Elmali et al. (2003) studied four patients of synovial chondromatosis, among these two are suffering from shoulder joint synovial chondromatosis. All four patients' have complaint about the pain in particular organ and restricted joint movement. Two shoulder joint synovial chondromatosis patients, were treated by arthrotomy followed by synovectomy and the loose bodies were removed.

After treatment, all patients became asymptomatic and no evidence of recurrent disease was detected. Result of study suggested that extraction of the loose bodies and arthroplasty are the best treatment for severe osteoarthritis. Similarly, Khorsandi (2007) also studied the two cases of shoulder synovial chondromatosis, both the patients were initially treated with arthroscopic debridement. Later on one patient were went for second arthroscopy and partial synovectomy while the while the second one have treated only by arthroscopy. Result of this study revealed that arthroscopic surgery are better option than the open synovectomy and arthroscopic surgery help the patients to return to normal activity much sooner than a formal open synovectomy. (Khorsandi , 2007). Further, Trajkovski et al. (2011) reported a case of extensive synovial chondromatosis in the right shoulder and surrounding soft tissues with extensive erosion up to the humeral head. These researchers operated combined anterior and posterior surgical excision of the cartilaginous fragments, and described insertion of an osteoarticular allograft to repair the humeral head defect and secondary anterior glenohumeral joint instability and fount better results (Trajkovski, 2011).

A case of synovial chondromatosis which excision of lesion was also reported by (Khandker \& Islam, 2010), these researchers also justify the importance of open arthrotomy in the treatment of shoulder joint.

\section{Conclusion}

Result of study and available literature suggested that early management of synovial chondromatosis help in the prevention of secondary degeneration of cartilage and help in the enjoy better and pain free life. Occasionally, osteocartilagenous loose bodies are not in higher number but the larger size may cause more severe synovial 
chondromatosis. Result of study and literature review suggests open arthrotomy for the treatment of synovial chondromatosis rather than arthroscopic procedure till advanced arthroscopic technique to prevent repeated surgery or recurrence of mechanical symptoms.

\section{Conflict of interest}

Authors would hereby like to declare that there is no conflict of interests that could possibly arise.

\section{References}

Butt SH, Muthukumar T, Cassar-Pullicino VN, Mangham DC (2005) Primary synovial osteochondromatosis presenting as constrictive capsulitis. Skeletal Radiology 34:707-713.

Chong CC, Kneebone A, Kirsh G (2007) Radiotherapy in the management of recurrent synovial chondromatosis. Australasian Radiology 51: 95-98. doi:10.1111/j.14401673.2006.01669.x.

Crotty JM, Monu JU, Pope TL Jr (1996). Synovial osteochondromatosis. Radiologic Clinics of North America 34: 327-342.

Davis RI, Foster H, Arthur K, Trewin S, Hamilton PW, Biggart DJ (1998a) Cell proliferation studies in primary synovial chondromatosis The Journal of Pathology 184:18-23. DOI: $\quad 10.1002 /($ SICI)1096-9896(199801)184:1<18::AIDPATH956>3.0.CO;2-J.

Davis RI, Hamilton A, Biggart JD (1998b) Primary synovial chondromatosis: a clinicopathologic review and assessment of malignant potential. Human Pathology 29 : 683-688. doi:10.1016/S0046-8177(98)90276-3.

Dorfman HD, Czerniak B (1998) Synovial lesions. In: Bone tumors. St Louis, Mo: Mosby, 1998; 1041-1086.

Elmali N, Esenkaya I, Alkan A (2003) Synovial chondromatosis: a report of four cases with three diverse localizations. Acta Orthopaedica et Traumatologica Turcica 37:173-177.

Fanburg-Smith JC (2003) Cartilage and bone-forming tumors and tumor-like lesions. In: Miettinen M (Ed.) Diagnostic soft tissue pathology. Philadelphia, Pa: Churchill-Livingstone, 2003; 403-425.

Hopyan S, Nadesan P, Yu C, Wunder J, Alman BA (2005) Dysregulation of hedgehog signalling predisposes to synovial chondromatosis. The Journal of Pathology 206:143-150. DOI: 10.1002/path.1761.

Jaffe HL (1958) Tumors and tumorous conditions of the bones and joints. London, England: Kimpton, 1958.
Kenan S, Abdelwahab IF, Klein MJ, Lewis MM (1993) Case report 817: Synovial chondrosarcoma secondary to synovial chondromatosis. Skeletal Radiology 122 : 623-626.

Khandker HH, Islam SH (2010) Primary Synovial Chondromatosis of Shoulder: A Case Report. Dinajpur Medical College 3 :94-96.

Khorsandi AA (2007) Arthroscopic treatment of synovial chondromatosis of the shoulder joint: case report and review. Medical Journal of Islamic Republic of Iran 21 :118-122.

Leo A, Nocera S (1981) Condromatyosi sinoviale della borsa sottoacromion deltoidea (considerazioni su di un caso). Chir Organi Mov 67 :605-608.

Mertens F, Jonsson K, Willén H, Rydholm A, Kreicbergs A, Eriksson L, Olsson-Sandin G, Mitelman F, Mandahl N (1996) Chromosome rearrangements in synovial chondromatous lesions. British Journal of Cancer 74 : 251-254.

Miligram JW (1977) Synovial osteochondromatosis. The Journal of Bone \& Joint Surgery 59-A:792.

Murphey MD, Vidal JA, Fanburg-smith JC, Gajewski DA (2007)Imaging of synovial chondromatosis with radiologicpathologic correlation. Radiographics 27 : 1465-1488. DOI: http://dx.doi.org/10.1148/rg.275075116.

Murphy FP, Dahlin DC, Sullivan CR (1962) Articular synovial chondromatosis. The Journal of Bone \& Joint Surgery 44:7786.

Roulot E, Le Viet D (1999) Primary synovial osteochondromatosis of the hand and wrist: report of a series of 21 cases and literature review. Revue du Rhumatisme 66:256-266.

Springer KR (1991) Synovial chondromatosis. The Journal of Food Surgery 30:446 - 449.

Sviland L, Malcolm AJ (1995) Synovial chondromatosis presenting as painless soft tissue mass: A report of 19 cases. Histopathology 27: 275-279. DOI: $10.1111 / \mathrm{j} .1365-$ 2559.1995.tb00221.x.

Tachdjian MO (1990) Pediatric Orthopedics, 2nd ed. Philadelphia: W.B. Saunders.

Trajkovski T, Mayne IP, Deheshi BM, Ferguson PC (2011) Synovial chondromatosis of the shoulder: open synovectomy and insertion of osteoarticular allogaft with internal fixation to repair intraoperative glenohumeral joint instability.. American Journal of Orthopedics 40 :E154-E158.

Trias A, Quintana O (1976) Synovial chondrometaplasia: review of world literature and a study of 18 Canadian cases. Canadian Journal of Surgery 19:151-158. 
Varma BP, Ramakrishna YJ (1976) Synovial chondromatosis of the shoulder. ANZ Journal of Surgery $46: 44-45$.
Volpin G, Nerubay J, Oliver S Katznelson A (1980) Synovial osteochondromatosis of the shoulder joint. The American Journal of
Surgery
46

:422-424. 